\section{Japan no help to rain forests}

\section{Tokyo}

JAPAN is severely criticized for its role in the destruction of the world's tropical rain forests in an analysis of its tropical timber trade released last week by the Worldwide Fund for Nature (WWF, still known in the United States as the World Wildlife Fund).

The report, compiled for WWF by a French economist and the head of the (JATAN), is the first comprehensive analysis of Japan's tropical timber trade, world market. It claims that over the past 30 years, a combination of Japan's trade and foreign aid policy, a booming economy and wasteful consumption of wood has led to the systematic destruction of rain forests in much of South-East Asia.

Japan's overseas development assistance (ODA), now the largest in the world at $\$ 11,000$ million in 1989 , comes in for particularly severe criticism in the report. Funds have been used to finance the construction of dams and roads (often designed and built by Japanese companies) which have destroyed rain forests and damaged the health and economic welfare of local populations in several South-East Asian countries.

The report criticizes the management of ODA, claiming there is no central organization coordinating Japan's aid policy and that responsibility is dispersed among several ministries and agencies. The Ministry of Foreign Affairs is supposed to play a coordinating role but other ministries, in particular the Ministry of International Trade and Industry and the Ministry of Agriculture, Forestry and Fisheries, have a strong voice in many ODA projects. Despite the large number of agencies Japan Tropical Forest Action Network which accounts for nearly a third of the

\section{UNIVERSITY DISPUTE}

\section{Research councils to award studentships}

\section{London}

There is no end in sight to the 14-weekold dispute over university lecturers' pay after members of the lecturers' union, the Association of University Teachers, voted by a narrow margin to reject the latest offer of the Committee of Vice-Chancellors and Principals. In a ballot held last week there was a 70 per cent turnout; 47 per cent of members voted in favour of accepting the offer of a 6.5 per cent pay increase, and 53 per cent voted against.

Disruption of examinations is likely to be minimized, however, now that the union is considering reducing the action from a boycott of all work related to examinations to a boycott only of marking examination papers. The union's council will decide on 22 April whether to accept this recommendation from its executive. involved, there is a lack of trained ODA staff in Japan compared with other developed nations.

Japan's ODA projects also lack adequate environmental impact assessments, according to the report. Assessments for ODA projects were introduced in 1980 but are voluntary and confidential and lack the influence to do more than modify a project.

The report calls on the Japanese government to establish binding environmental impact assessments that will be open to public discussion. It recommends a committee of representatives of related ministries, the timber industry and nongovernmental organizations (NGOs) be set up to formulate a plan of action for conservation of tropical rain forests, and a code of conduct be written that would restrict trade to timber from sustainable resources. The report urges Japan's industry to follow recent proposals from the European timber industry and contribute to a fund to promote sustainable forestry through the International Timber Trade Organization. Finally, the report calls for a nationwide campaign to reduce Japan's wasteful and unnecessary consumption of tropical timber, particularly in the paper and construction industry.

The WWF report comes at a time when there is growing concern worldwide about the effects of rain-forest destruction on global climate. But, as the report points out, there are very few people within Japanese government ministries and agencies who have expertise in assessing the environmental impact of the timber trade and ODA on rain forests. Even Japan's NGOs, including WWF Japan, lack such experts.

David Swinbanks

\section{$Z^{0}$ factory makes ready}

\section{Berkeley}

The Stanford Linear Collider (SLC) passed a major milestone on 12 April, with the production of its first $Z^{0}$ particle. Repairs carried out over the autumn and winter have boosted the instrument's reliability tenfold and Stanford Linear Accelerator Center (SLAC) officials expect to produce several thousand $Z^{0}$ particles by the end of the summer, enough to determine the mass of the particle and to begin to analyse its lifetime and decay modes.

SLC uses a pair of curved arcs to guide electron and positron bunches from a linear accelerator onto a collision course. The design, conceived by SLAC director Burton Richter, provides an inexpensive alternative to the circular Large ElectronPositron Collider (LEP) due to come on line this summer at CERN in Geneva.

Although SLC began with a two-year lead over LEP in the race to characterize the $Z^{0}$ particle, most of that time has been lost overcoming technical difficulties in commissioning the new machine. The beams first met last spring, but high background in the detection chamber and low reliability of operation forced the shutdown of the machine for repairs last September (see Nature 335, 285; 1988).

During last autumn and winter, new magnets called muon spoilers were added to SLC, to deflect background muons away from the detector. A slight misalignment in the damping ring where positrons are stored was also discovered and repaired.

Last week, SLC began running at an efficiency that should produce one $Z^{0}$ particle per day, according to SLAC spokesman Michael Riordan. But Richter warned that "many months of hard work lie ahead" before it will be operating at design specifications, which should produce $3,000 \mathrm{Z}^{0}$ particles per day.

SLC's design specifications call for A boycott of marking will cause a delay in the announcement of degree results. This poses problems for the research councils in their allocation of postgraduate research studentships, as these depend on students receiving a first or upper-second class degree. If results are not available before the end of July, four of the councils (Science and Engineering, Natural Environment, Medical Research, and Agricultural and Food) have agreed that studentships will be awarded on provision of a written guarantee from heads of department or from vice-chancellors, saying that on the evidence available from continuous assessment and referees' reports the student is likely to gain the required standard of degree. The Economic and Social Research Council may adopt a different procedure.

Christine McGourty 60,000 million electrons and positrons per bunch, with a bunch radius of $1.6 \mu \mathrm{m}$, and a pulse rate of 120 per second. The machine is now running at 15,000 million electrons or positrons per bunch, with a bunch radius of $4 \mu \mathrm{m}$ and a pulse rate of 30 per second. Riordan said fine tuning over the next few months is expected to bring down bunch radius and background, increasing the number of $Z^{\prime \prime}$ s produced. But several additions will be needed before the instrument can operate at full power. A new cooling tower, new positron source and additional power for the damping rings will be completed and installed in the autumn and superconducting magnets for narrowing the beams added later on. The additions scheduled for this year are all within the SLC's \$100-million budget for 1989, said Riordan, although support for 1990 has to be found. Marcia Barinaga 